\title{
The Impact of Insulin Pump Therapy on Glycemic Profiles in Patients with Type 2 Diabetes: Data from the OpT2mise Study
}

\author{
Ignacio Conget, MD, Javier Castaneda, MSc, ${ }^{2}$ Goran Petrovski, MD, Bruno Guerci, MD, \\ Anne-Sophie Racault, $\mathrm{MSc}_{1}^{5}$ Yves Reznik, MD, ${ }^{6}$ Ohad Cohen, MD, Sarah Runzis, MSc, \\ Simona de Portu, $\mathrm{PhD}^{5}$ and Ronnie Aronson, $\mathrm{MD}^{7}$ for the OpT2mise Study Group*
}

\begin{abstract}
Background: The OpT2mise randomized trial was designed to compare the effects of continuous subcutaneous insulin infusion (CSII) and multiple daily injections (MDI) on glucose profiles in patients with type 2 diabetes. Research Design and Methods: Patients with glycated hemoglobin $\left(\mathrm{HbA}_{1 \mathrm{c}}\right)$ levels of $\geq 8 \%(64 \mathrm{mmol} / \mathrm{mol})$ and $\leq 12 \%(108 \mathrm{mmol} / \mathrm{mol})$ despite insulin doses of $0.7-1.8 \mathrm{U} / \mathrm{kg} /$ day via MDI were randomized to CSII $(n=168)$ or continued MDI $(n=163)$. Changes in glucose profiles were evaluated using continuous glucose monitoring data collected over 6-day periods before and 6 months after randomization.

Results: After 6 months, reductions in $\mathrm{HbA}_{1 \mathrm{c}}$ levels were significantly greater with CSII $(-1.1 \pm 1.2 \%$ $[-12.0 \pm 13.1 \mathrm{mmol} / \mathrm{mol}])$ than with MDI $(-0.4 \pm 1.1 \%[-4.4 \pm 12.0 \mathrm{mmol} / \mathrm{mol}])(P<0.001)$. Similarly, compared with patients receiving MDI, those receiving CSII showed significantly greater reductions in 24-h mean sensor glucose (SG) (treatment difference, $-17.1 \mathrm{mg} / \mathrm{dL} ; P=0.0023)$, less exposure to $\mathrm{SG}>180 \mathrm{mg} / \mathrm{dL}(-12.4 \%$; $P=0.0004)$ and $\mathrm{SG}>250 \mathrm{mg} / \mathrm{dL}(-5.5 \% ; P=0.0153)$, and more time in the SG range of $70-180 \mathrm{mg} / \mathrm{dL}(12.3 \%$; $P=0.0002$ ), with no differences in exposure to $\mathrm{SG}<70 \mathrm{mg} / \mathrm{dL}$ or in glucose variability. Changes in postprandial (4-h) glucose area under the curve $>180 \mathrm{mg} / \mathrm{dL}$ were significantly greater with CSII than with MDI after breakfast $(-775.9 \pm 1,441.2 \mathrm{mg} / \mathrm{dL} / \mathrm{min}$ vs. $-160.7 \pm 1,074.1 \mathrm{mg} / \mathrm{dL} / \mathrm{min} ; \quad P=0.0015)$ and after dinner $(-731.4 \pm 1,580.7 \mathrm{mg} / \mathrm{dL} / \mathrm{min}$ vs. $-71.1 \pm 1,083.5 \mathrm{mg} / \mathrm{dL} / \mathrm{min} ; P=0.0014)$.

Conclusions: In patients with suboptimally controlled type 2 diabetes, CSII significantly improves selected glucometrics, compared with MDI, without increasing the risk of hypoglycemia.
\end{abstract}

\section{Introduction}

$\mathbf{F}$ OR PATIENTS WITH TYPe 2 Diabetes who require insulin therapy, continuous subcutaneous insulin infusion (CSII) provides a potential alternative to multiple daily injections
(MDI) for insulin delivery. ${ }^{1}$ However, although the use of CSII has been well documented in type 1 diabetes, relatively few studies with this therapy in type 2 diabetes have been published to date. ${ }^{1,2}$ The recent OpT2mise study was a randomized controlled trial that compared the efficacy of CSII

\footnotetext{
${ }^{1}$ Diabetes Unit, Endocrinology and Nutrition Department, University Hospital Clinic, Barcelona, Spain.

${ }^{2}$ Medtronic Bakken Research Center, Maastricht, The Netherlands.

${ }^{3}$ University Clinic of Endocrinology, Skopje, Macedonia.

${ }_{5}^{4} \mathrm{CHU}$ de Nancy, Vandoeuvre-Les-Nancy, France.

${ }^{5}$ Medtronic International Trading Sàrl, Tolochenaz, Switzerland.

${ }^{6}$ Department of Endocrinology, University of Caen Côte de Nacre Regional Hospital Center, Caen, France.

${ }^{7}$ LMC Diabetes \& Endocrinology, Toronto, Ontario, Canada.

*Members of the OpT2mise Study Group are given in the Appendix.

This study is registered with ClinicalTrials.gov with clinical trial registration number NCT01182493.

Some of the data reported in this article have previously been reported at the 2014 Congress of the European Association for the Study of Diabetes and the 2015 Congress of the International Conference on Advanced Technologies \& Treatments for Diabetes.

(C) Ignacio Conget, et al., 2016; Published by Mary Ann Liebert, Inc. This Open Access article is distributed under the terms of the Creative Commons Attribution Noncommercial License (http://creativecommons.org/licenses/by-nc/4.0/) which permits any noncommercial use, distribution, and reproduction in any medium, provided the original author(s) and the source are credited.
} 
and MDI in patients with type 2 diabetes who had previously been unable to reach glycated hemoglobin $\left(\mathrm{HbA}_{1 \mathrm{c}}\right)$ targets despite using intensified MDI regimens. ${ }^{3}$ After 6 months, there was a significant between-group treatment difference of $-0.7 \%(7.7 \mathrm{mmol} / \mathrm{mol})$ in $\mathrm{HbA}_{1 \mathrm{c}}$ levels, favoring the use of CSII, with no increase in the risk of hypoglycemia. ${ }^{3}$

$\mathrm{HbA}_{1 \mathrm{c}}$ is the glycemic control marker most linked to complications of diabetes and remains the key target of disease management. ${ }^{4}$ However, it does not fully characterize day and night glucose profiles, which are needed to understand how best to adjust treatment, particularly insulin therapy. The use of continuous glucose monitoring (CGM) provides the opportunity to observe glycemic patterns over specified time periods, ${ }^{5,6}$ and blinded CGM can be used to help determine glycemic variability, providing valuable information on the effectiveness and safety of experimental interventions. ${ }^{7}$ To date, however, few studies have investigated the use of CGM in patients with type 2 diabetes receiving intensive MDI or CSII therapy. ${ }^{8,9}$ For this reason, a secondary objective of the OpT2mise study was to compare the effects of CSII and MDI on glucose profiles obtained using CGM data in patients with suboptimally controlled type 2 diabetes. The results of this analysis are reported here.

\section{Research Design and Methods}

OpT2mise was a multicenter, international, randomized, controlled, parallel-group study to evaluate the comparative efficacy and safety of CSII and MDI regimens in insulin-using patients with type 2 diabetes that was suboptimally controlled with advanced basal-bolus therapy. It was performed at 36 centers in Canada, Europe, Israel, South Africa, and the United States, and all patients provided written informed consent.

The study methods have been reported in full elsewhere $^{3,10}$ In brief, subjects with poor glycemic control $(n=495)$ on MDI were enrolled into a run-in period for insulin dose optimization ( $\geq 0.7$ and $\leq 1.8 \mathrm{U} / \mathrm{kg} /$ day), after which those in whom control remained suboptimal (HbA1c $\geq$ $8 \%$ [64 mmol $/ \mathrm{mol}]$ and $\leq 12 \%$ [108 mmol/mol]) were randomly assigned to receive CSII or continued MDI for 6 months. Blinded CGM data were obtained using the Medtronic $i$ Pro $2^{\mathrm{TM}}$ CGM system (Medtronic, Northridge, CA), with glucose data recorded over 6 days before randomization (at the end of the run-in intensification period, referred to as baseline) and on completion of 6 months of randomized treatment. The mean absolute relative difference of the sensors was calculated.

The primary end point of the study was the between-group difference in change in mean $\mathrm{HbA}_{1 \mathrm{c}}$ from baseline to the end of the randomized phase. Secondary end points included changes from baseline to 6 months in CGM parameters, including mean 24-h glucose levels, the area under the curve for hypoglycemia (defined as sensor glucose [SG] values $\leq 70 \mathrm{mg} / \mathrm{dL}$ ) and hyperglycemia ( $\mathrm{SG}$ values $\geq 180 \mathrm{mg} / \mathrm{dL}$ ), and the time spent in hypoglycemia and hyperglycemia. Areas under the curve were calculated as the product of the magnitude and duration of sensor-measured glucose values above or below the specified thresholds. Information on glucose variability, including SD, mean amplitude of glucose excursions, and continuous overlapping net glycemic action (CONGA) (over a 60-min interval), was also collected as a secondary end point. In addition, the impact of CSII on postprandial (4-h) glucose profiles was evaluated. For this analysis, breakfast time was arbitrarily defined as ranging from 06:00 to 09:00 $\mathrm{h}$ inclusive, lunch time from 11:30 to 15:00 $\mathrm{h}$ inclusive, and dinner time from 16:30 to $22: 30 \mathrm{~h}$ inclusive, in order to accommodate differences in meal patterns between countries.

\section{Statistical analysis}

The full description of the statistical plan of the OpT2mise trial has been published in detail elsewhere. ${ }^{10}$ The present analysis of glucose profiles was based on available CGM data, with no imputation of missing values. In order to maximize the consistency of CGM data, only data from at least two consecutive 24-h periods of CGM were included in the analysis. Continuous end points were analyzed with a two-sided, two-sample, $t$ test. Analyses were performed with SAS version 9.3 software (SAS Institute, Cary, NC), and $P$ values $<0.05$ were considered to be statistically significant.

\section{Results}

In total, 590 patients were assessed for eligibility, of whom 495 entered the 2-month run-in phase during which insulin dosage was optimized. Of these, 331 had suboptimal glycemic control, defined as an $\mathrm{HbA}_{1 \mathrm{c}}$ level of $\geq 8 \%$ (64 mmol/ $\mathrm{mol})$ and $\leq 12 \%(108 \mathrm{mmol} / \mathrm{mol})$, at the end of the run-in phase and were randomized to CSII $(n=168)$ or continued MDI $(n=163)$. Baseline characteristics of the randomized patients are summarized in Table 1 . The mean $( \pm \mathrm{SD})$ age was $56.0 \pm 9.6$ years, the mean duration of diabetes was $15.1 \pm 8.0$ years, and mean $\mathrm{HbA}_{1 \mathrm{c}}$ level was $9.0 \pm 0.8 \%(75 \pm 8.7 \mathrm{mmol} / \mathrm{mol})$.

As previously described, ${ }^{3}$ at 6 months the mean $\mathrm{HbA}_{1 \mathrm{c}}$ level had decreased to $7.9 \%(63 \mathrm{mmol} / \mathrm{mol})$ in the CSII group (mean change, $-1.1 \pm 1.2 \%[-12.0 \pm 13.1 \mathrm{mmol} / \mathrm{mol}]$ ) and to $8.6 \%(70 \mathrm{mmol} / \mathrm{mol})$ in the MDI group (mean change, $-0.4 \pm 1.1 \%[-4.4 \pm 12.0 \mathrm{mmol} / \mathrm{mol}]$ ). The betweengroup difference was statistically significant in favor of CSII $(-0.7 \%$; $95 \%$ confidence interval $[\mathrm{CI}],-0.9,-0.4 \%$ [-7.7 mmol $/ \mathrm{mol}(95 \% \mathrm{CI},-8.6,-4.4 \mathrm{mmol} / \mathrm{mol})] ; P<0.001)$.

Table 1. Baseline Characteristics of RANDOMIZED SUBJECTS

\begin{tabular}{lcc}
\hline & $C S I I$ & $M D I$ \\
\hline $\begin{array}{l}\text { Number of patients } \\
\text { Age (years) }\end{array}$ & 168 & 163 \\
$\begin{array}{l}\text { Gender } \\
\quad \text { (men/women) }\end{array}$ & $55.5 \pm 9.7$ & $56.4 \pm 9.5$ \\
$\begin{array}{l}\text { Duration of diabetes } \\
\quad(\text { years) }\end{array}$ & $14.9 \pm 8.0$ & $15.3 \pm 8.0$ \\
$\begin{array}{l}\text { Body mass } \\
\text { index (kg/m }{ }^{2} \text { ) }\end{array}$ & $33.5 \pm 7.5$ & $33.2 \pm 7.0$ \\
$\begin{array}{l}\text { HbA1c } \\
\quad \text { \% (mmol/mol)] }\end{array}$ & $9.0 \pm 0.8(75 \pm 8.7)$ & $9.0 \pm 0.8(75 \pm 8.7)$ \\
$\begin{array}{l}\text { Total daily insulin dose (units/day) } \\
\quad \text { Long-acting }\end{array}$ & $57.4 \pm 30.3$ & \\
$\quad$ Rapid-acting & $55.6 \pm 31.7$ & $52.4 \pm 27.7$ \\
$\begin{array}{l}\text { Insulin dose } \\
\quad \text { (units/kg/day) }\end{array}$ & $1.1 \pm 0.4$ & $53.8 \pm 30.8$ \\
$\begin{array}{l}\text { Metformin use } \\
\text { Metformin }\end{array}$ & $120(71 \%)$ & $1.1 \pm 0.4$ \\
$\quad$ dose (mg) & $1,810 \pm 680$ & $112(69 \%)$ \\
\hline
\end{tabular}

Data are presented as mean $\pm \mathrm{SD}$ values or as number (percentage), as indicated.

CSII, continuous subcutaneous insulin infusion; $\mathrm{HbA}_{1 \mathrm{c}}$, glycated hemoglobin; MDI, multiple daily injections. 
Table 2. Changes in Continuous Glucose Monitoring Variables from Baseline to 6 Months

\begin{tabular}{lccc}
\hline & & MDI & $\begin{array}{c}\text { Between-group } \\
\text { difference }\end{array}$ \\
\hline Change in 24-h mean glucose concentration $(\mathrm{mg} / \mathrm{dL})$ & $-23.0 \pm 42.6$ & $-5.9 \pm 30.2$ & $-17.1^{\mathrm{a}}$ \\
AUC change $>180 \mathrm{mg} / \mathrm{dL}(\mathrm{mg} / \mathrm{dL} / \mathrm{min})$ & $-11.5 \pm 25.5$ & $-2.2 \pm 15.8$ & $-9.3^{\mathrm{a}}$ \\
Change in time spent $>180 \mathrm{mg} / \mathrm{dL}(\mathrm{min} / 24 \mathrm{~h})$ & $-225.6 \pm 355.9$ & $-56.8 \pm 256.3$ & $-168.7^{\mathrm{b}}$ \\
AUC change $<70 \mathrm{mg} / \mathrm{dL}(\mathrm{mg} / \mathrm{dL} / \mathrm{min})$ & $0.0 \pm 0.5$ & $-0.1 \pm 0.9$ & $0.1(\mathrm{NS})$ \\
Change in time spent $<70 \mathrm{mg} / \mathrm{dL}(\mathrm{min} / 24 \mathrm{~h})$ & $8.8 \pm 49.6$ & $5.1 \pm 71.0$ & $3.7(\mathrm{NS})$ \\
\hline
\end{tabular}

Data are mean $\pm \mathrm{SD}$ values.

${ }^{\mathrm{a}} P<0.01,{ }^{\mathrm{b}} P<0.001$.

AUC, area under the curve; CSII, continuous subcutaneous insulin infusion; NS, not significant.

At baseline, blinded CGM data were available for 125 patients in the CSII group (74.4\%) and $135(82.2 \%)$ in the MDI group; the corresponding values at 6 months were 108 $(64.3 \%)$ and $101(62.0 \%)$, respectively. Baseline mean absolute relative difference of blinded sensors was $11.2 \pm 6.2 \%$ and $10.7 \pm 5.4 \%$ in the CSII and MDI groups, respectively; the corresponding values at 6 months were $12.9 \pm 5.6 \%$ and $12.0 \pm 7.9 \%$, respectively. The baseline characteristics of patients with available CGM data did not differ significantly from those of the overall randomized population.

The mean daily number of self-monitoring blood glucose (SMBG) measurements at baseline was $4.1 \pm 1.2$ in the CSII group and $4.1 \pm 1.2$ in the MDI group; the corresponding values at 6 months were $4.7 \pm 2.0$ and $4.2 \pm 1.7$, respectively. There were no significant between-group differences in the change in the mean number of SMBG measurements from baseline $(P=0.079)$.

Changes in SG data from baseline to 6 months are summarized in Table 2. Compared with the MDI group, patients receiving CSII showed significantly greater reductions in 24-h mean SG (mean treatment difference, $-17.1 \mathrm{mg} / \mathrm{dL}$; $P=0.0023)$, less time of exposure to $\mathrm{SG}>180 \mathrm{mg} / \mathrm{dL}(-12.4 \%$; $P=0.0004)$ and $\mathrm{SG}>250 \mathrm{mg} / \mathrm{dL}(-5.5 \% ; P=0.0153)$, and more time with SG within the target range of $70-180 \mathrm{mg} / \mathrm{dL}$ $(12.3 \% ; P=0.0002)$. There was no difference in time with exposure to $\mathrm{SG}<70 \mathrm{mg} / \mathrm{dL}$ between the groups.

Similar results were obtained when the analyses were adjusted by the number of SMBG measurements performed both during the whole study phase (6 months) and during the time that the blinded CGM data were collected.

There were no significant differences in measures of glucose variability between the groups. The mean change in 24-h SG SD from baseline to 6 months was $-3.9 \pm 13.9 \mathrm{mg} / \mathrm{dL}$ (95\% CI, $-6.8,-1.0)$ in the CSII group, compared with $-3.6 \pm 14.2 \mathrm{mg} /$ $\mathrm{dL}(95 \% \mathrm{CI},-6.6,-0.6)$ in the MDI group. Similarly, the mean changes in mean amplitude of glucose excursions from baseline to 6 months were $-5.2 \pm 35.6(95 \% \mathrm{CI},-12.7,2.3)$ and $-8.8 \pm 33.4 \mathrm{mg} / \mathrm{dL}(95 \% \mathrm{CI},-15.8,-1.8)$, respectively. The mean changes in CONGA from baseline to 6 months were $-2.3 \pm 10.3$ in the CSII group and $-1.8 \pm 9.9 \mathrm{mg} / \mathrm{dL}$ in the MDI group (between-group difference, -0.55 [95\% CI, -3.47 , 2.36]; $P=0.71$ ). CGM data at baseline and at 6 months are summarized in Figure 1, which presents a visual representation of the modal day, in which all collected data over multiple days are shown over a single $24-\mathrm{h}$ period, starting and ending at midnight. Figure 1 shows that, at 6 months, CSII resulted in decreases in median SG values during the night, postbreakfast, during the late afternoon, and postdinner, compared with MDI.
The evaluation of postprandial glucose profiles showed that the decrease in 4-h postprandial hyperglycemia, measured as the area under the curve $\geq 180 \mathrm{mg} / \mathrm{dL}$, was significantly greater with CSII than with MDI after breakfast $(-775.9 \pm$ $1,441.2 \mathrm{mg} / \mathrm{dL} / \mathrm{min}$ vs. $-160.7 \pm 1,074.1 \mathrm{mg} / \mathrm{dL} / \mathrm{min}$, respectively; $P=0.0015)$ and after dinner $(-731.4 \pm 1,580.7 \mathrm{mg} / \mathrm{dL} /$ min vs. $-71.1 \pm 1,083.5 \mathrm{mg} / \mathrm{dL} / \mathrm{min}$, respectively; $P=0.0014)$; the difference in area under the curve after lunch did not reach statistical significance $(-465.0 \pm 1,565.0 \mathrm{mg} / \mathrm{dL} / \mathrm{min}$ vs. $-180.0 \pm 1,272.0 \mathrm{mg} / \mathrm{dL} / \mathrm{min}$ ). There was no significant difference between the groups in the change in 1-h postprandial CONGA from baseline (between-group difference, -1.6 [95\% CI, -4.7, 1.6] at breakfast, -1.0 [95\% CI, -4.4, 2.5] at lunch, and $0.6[95 \% \mathrm{CI},-2.6,3.9]$ at dinner).

\section{Discussion}

The results of this analysis show that, compared with basal-bolus therapy with insulin analogs, CSII treatment in suboptimally controlled patients with type 2 diabetes provides a significant improvement in glucose profile, with increased time spent in the target glucose range, without increasing the time spent in hypoglycemia.

In routine clinical practice, assessment of glycemic control is typically performed using $\mathrm{HbA}_{1 \mathrm{c}}$ in combination with fasting blood glucose and capillary SMBG profiles. ${ }^{11}$ Blinded CGM allows a more detailed glucose profile to be constructed, which overcomes the limitations of intermittent and sometimes unrepresentative data provided by SMBG. ${ }^{6,12}$ OpT2mise is one of the few comparative studies of CSII and MDI in patients with type 2 diabetes that includes data on glycemic control as measured by CGM. ${ }^{8,9}$ This analysis from OpT2mise showed that the time spent in the glucose target range commonly used in clinical practice $(70-180 \mathrm{mg} / \mathrm{dL})$ was significantly higher in patients using CSII than in those using MDI. The observed $17 \mathrm{mg} / \mathrm{dL}$ reduction in $24-\mathrm{h}$ mean $\mathrm{SG}$ concentrations seen in the CSII group is consistent with the $0.7 \%(7.7 \mathrm{mmol} / \mathrm{mol})$ difference in $\mathrm{HbA}_{1 \mathrm{c}}$ level at 6 months. ${ }^{13}$ In addition, patients using CSII had significantly less exposure to hyperglycemia, defined as glucose concentrations above $180 \mathrm{mg} / \mathrm{dL}$ or $250 \mathrm{mg} / \mathrm{dL}$.

An important concern relating to the intensification of insulin therapy in patients with type 2 diabetes is the increased risk of hypoglycemia. ${ }^{14,15}$ In addition to being a cause of morbidity and worsening quality of life, recurrent hypoglycemia may compromise the long-term maintenance of glycemia. ${ }^{16-19}$ It is important that, in this study, the reduction in exposure to hyperglycemia in the CSII group was not 
Baseline Median Daily Blood Glucose Profile

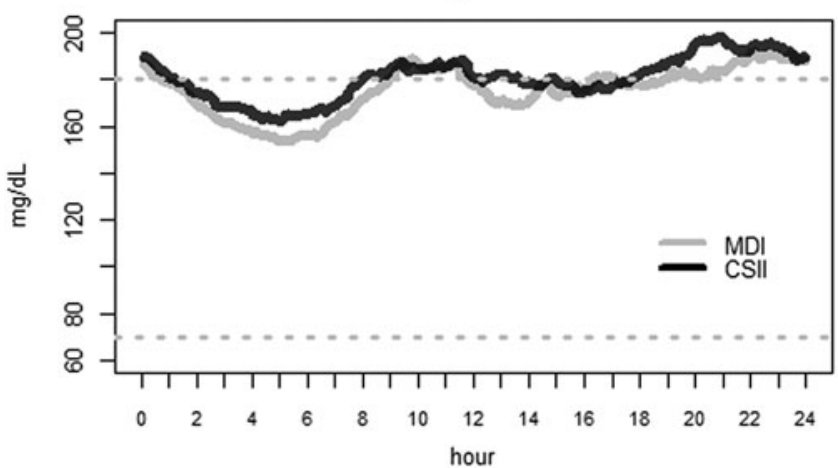

Baseline Daily Blood Glucose Variability

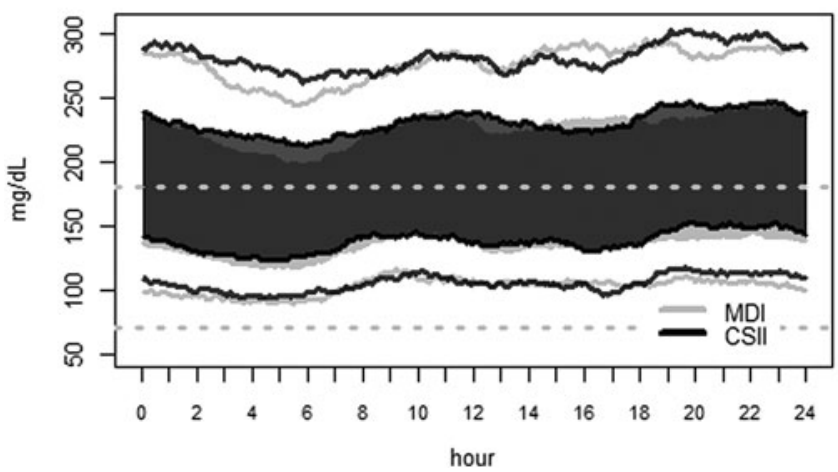

6 Months Median Daily Blood Glucose Profile

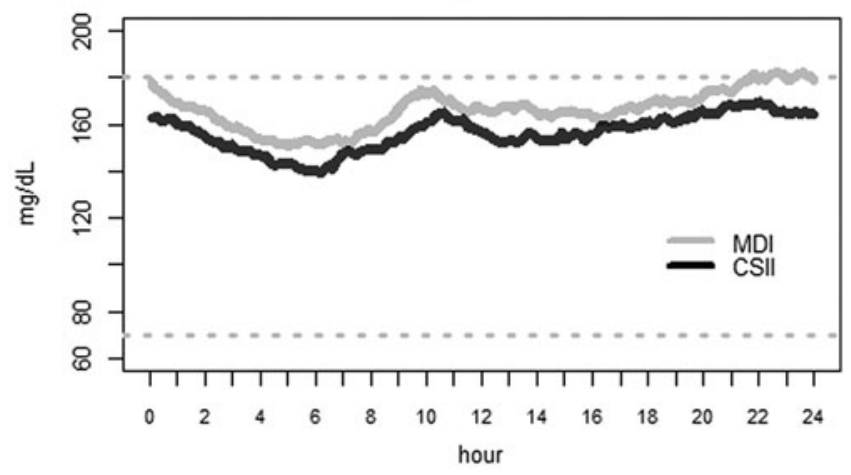

6 Months Daily Blood Glucose Variability

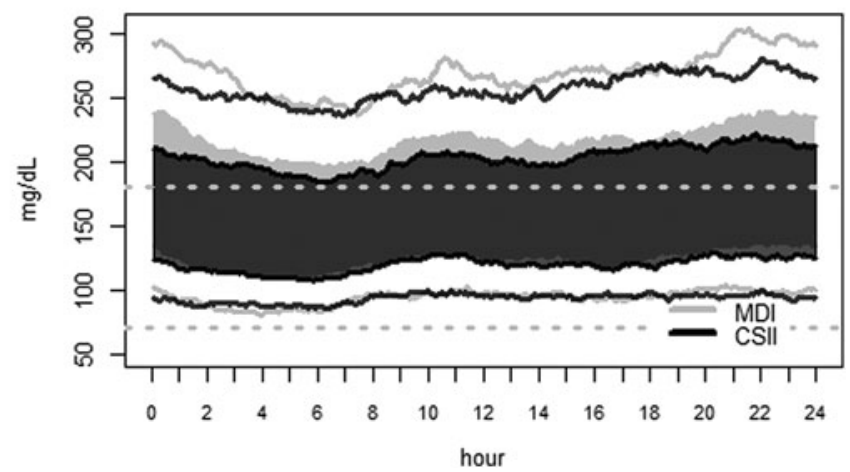

FIG. 1. Visual representation of the modal day, in which all collected data over multiple days are shown over a single 24$\mathrm{h}$ period, starting and ending at midnight. (Upper panels) Median daily blood glucose concentrations (left) at baseline and (right) after 6 months, in relation to the "normal" range $(70-180 \mathrm{mg} / \mathrm{dL})$, which is indicated by the dashed lines. (Lower panels) Daily blood glucose variability (left) at baseline and (right) after 6 months. The light gray area represents the interquartile range $\left(25^{\text {th }}\right.$ and $75^{\text {th }}$ percentiles) for the multiple daily injections (MDI) arm, whereas the corresponding range for the continuous subcutaneous insulin infusion (CSII) arm is shown in transparent dark gray (middle part of the plot); the interquartile ranges from both arms have been superimposed to facilitate visual comparisons. The black and gray lines at the bottom represent the $10^{\text {th }}$ percentile for the CSII and MDI arms, respectively, and the corresponding lines at the top represent the $90^{\text {th }}$ percentile for the CSII and MDI arms, respectively.

associated with an increase in time spent in hypoglycemia $(\mathrm{SG}<70 \mathrm{mg} / \mathrm{dL})$. Furthermore, as described previously, ${ }^{3}$ there was only one episode of severe hypoglycemia during the study, which occurred in the MDI group.

In addition to reductions in $\mathrm{HbA}_{1 \mathrm{c}}$ and SG, CSII was also associated with attenuation of postbreakfast and postdinner glucose concentrations. In epidemiological studies, high postprandial glucose concentrations have been associated with cardiovascular morbidity and mortality ${ }^{20}$; as a result, although the clinical significance of this relationship is still a matter of debate, ${ }^{21,22}$ control of postprandial glucose profiles is an objective of antidiabetes therapies in type 2 diabetes. ${ }^{11,23}$ When using MDI, this requires three or more daily injections of rapid-acting insulin analogs at mealtimes, whereas with CSII bolus insulin administration is required. In OpT2mise, the impact of pump therapy on postprandial glucose control, compared with MDI, was evaluated by measuring glucose concentrations over arbitrarily defined time frames for breakfast, lunch, and dinner, in order to allow for differences in mealtimes between the participating countries. The reason for the minimal effect of CSII on postlunch glucose excursions, compared with the significant reductions seen after breakfast and dinner, is unclear from this study and should be further assessed. Relevant factors may include differences in meal composition or bolus insulin doses, or omission of lunchtime insulin doses.

Glucose variability, as assessed by SD, mean amplitude of glucose excursions, and CONGA, improved to similar extents in both groups. This finding could be related to the lower glucose variability in patients with insulin-treated type 2 diabetes, compared with patients with type 1 diabetes, ${ }^{24,25}$ and to differences in the approach to pump therapy and overall management in the two settings. It does not preclude the possibility that patients with type 2 diabetes with less insulin resistance might benefit from a reduction in glucose variability with CSII, as has been seen in patients with type 1 diabetes switched to CSII. ${ }^{26}$ The role of glucose variability in the risk of developing chronic diabetes complications is still a matter of debate, ${ }^{24,25,27}$ but reducing variability could be considered a reasonable additional benefit of any antidiabetes therapeutic strategy. ${ }^{28}$

In addition to greater convenience for patients, as well as the reduced risk of missed insulin doses, it may be speculated that the advantages of CSII therapy arise mainly from the more favorable pharmacokinetics and pharmacodynamics of the basal insulin regimen; the daily basal-bolus ratio increased in CSII-treated patients, compared with those receiving MDI. ${ }^{3}$ It is noteworthy that, although patients on CSII 
therapy had access to a bolus calculator, this was used very rarely. Another advantage of CSII relates to the ability to obtain data on adherence to pump therapy, whereas adherence cannot be monitored in MDI users. Optimal adherence to insulin therapy is of paramount importance for maximizing treatment efficacy, and adherence in less compliant patients might be improved by switching to pump therapy.

Our study has some limitations. CGM data could not be obtained from the whole cohort of patients, although the characteristics of the patients for whom glucose profile data were available did not differ from those of the full randomized cohort. In addition, CGM is still not used routinely to evaluate glucose control in clinical practice, and its role in clinical studies is evolving. We are aware that longer periods of CGM data may be preferred to reflect variability, and this may be considered in future studies. ${ }^{29}$ Limitations associated with postprandial glucose assessment, including variations in meal patterns between countries and possible omission of lunchtime insulin doses, have been referred to above.

In summary, compared with MDI, CSII treatment in suboptimally controlled patients with type 2 diabetes provides a significant improvement in glucose profile, with increased time spent within target ranges and less exposure to hyperglycemia, without increasing time spent in hypoglycemia.

\section{Acknowledgments}

We thank the OpT2mise study team at Medtronic for their support, as well as the monitors, investigators, study coordinators, and patients for having done this trial. We also thank John Shin, Scott Lee, and Severine Liabat (employees of Medtronic) for their assistance throughout the conduct of the study. Medical writing and editorial assistance in the preparation of this article, funded by Medtronic, was provided by Dr. Michael Shaw (MScript Ltd., Hove, United Kingdom). The study was sponsored by Medtronic International Trading Sàrl, Tolochenaz, Switzerland.

\section{Author Disclosure Statement}

I.C. reports receiving lectures and consulting fees from Medtronic Inc., Bayer AG, GSK, Eli Lilly \& Co., NovoNordisk A/S, Sanofi-Aventis, Novartis, and MSD. Y.R. has undertaken clinical trials as a Co-Investigator for Medtronic, Eli Lilly, and Novo Nordisk. He has also provided advisory services to Medtronic, Abbott, and Eli Lilly and attended conferences organized by Eli Lilly and Medtronic as a contributor. G.P. has received speaker and consulting fees from Sanofi-Aventis, Medtronic, Eli Lilly, NovoNordisk, MSD, Roche Diagnostic, and Alkaloid. B.G. has received speaker and consulting fees from Bristol-Myers Squibb, Sanofi Aventis, GlaxoSmithKline, Novartis, Novo Nordisk, Eli Lilly, Boehringer Ingelheim, Janssen, Intarcia, Metacure, Pfizer, MSD, Roche Diagnostic, Medtronic, Menarini Diagnostic, Abbott, Vitalaire, Dinno Santé, and Orkyn. R.A. has received speaker and consulting fees from Eli Lilly, Novo Nordisk, Sanofi, and Medtronic. A.-S.R., J.C., O.C., S.d.P., and S.R. are full-time Medtronic employees. O.C. participated in the study as an investigator before joining Medtronic; all patients had completed the study at the time he joined Medtronic.

I.C., Y.R., O.C., R.A., S.R., S.d.P., and J.C. contributed to the study concept, designed the trial, and obtained research funding. J.C. provided statistical advice on trial design and drafted the analysis plan. I.C., Y.R., O.C., R.A., G.P., and B.G. collected data. All authors contributed to the acquisition and review of the data. S.R. and A.-S.R. coordinated the trial. J.C. analyzed the data. All authors contributed to the interpretation of data and the drafting of the report. They critically revised the report for important intellectual content and approved the version to be published. I.C. had full access to all data in the study, takes responsibility for the integrity of data and accuracy of data analysis, and wrote the article.

\section{References}

1. Grunberger G, Abelseth JM, Bailey TS, Bode BW, Handelsman Y, Hellman R, Jovanovic L, Lane WS, Raskin P, Tamborlane WV, Rothermel C: Consensus statement by the American Association of Clinical Endocrinologists/American College of Endocrinology Insulin Pump Management Task Force. Endocr Pract 2014;20:463-489.

2. Reznik Y, Cohen O: Insulin pump for type 2 diabetes: use and misuse of continuous subcutaneous insulin infusion in type 2 diabetes. Diabetes Care 2013;36(Suppl 2):S219-S225.

3. Reznik Y, Cohen O, Aronson R, Conget I, Runzis S, Castaneda J, Lee SW: Insulin pump treatment compared with multiple daily injections for treatment of type 2 diabetes (OpT2mise): a randomised open-label controlled trial. Lancet 2014;384:1265-1272.

4. Weykamp C: HbA1c: a review of analytical and clinical aspects. Ann Lab Med 2013;33:393-400.

5. Bode BW, Battelino T: Continuous glucose monitoring in 2012. Diabetes Technol Ther 2013;15(Suppl 1):S-13-S-23.

6. Bergenstal RM, Ahmann AJ, Bailey T, Beck RW, Bissen J, Buckingham B, Deeb L, Dolin RH, Garg SK, Goland R, Hirsch IB, Klonoff DC, Kruger DF, Matfin G, Mazze RS, Olson BA, Parkin C, Peters A, Powers MA, Rodriguez H, Southerland P, Strock ES, Tamborlane W, Wesley DM: Recommendations for standardizing glucose reporting and analysis to optimize clinical decision making in diabetes: the Ambulatory Glucose Profile (AGP). Diabetes Technol Ther 2013;15:198-211.

7. Patrascioiu I, Quiros C, Rios P, Ruiz M, Mayordomo R, Conget I, Gimenez M: Transitory beneficial effects of professional continuous glucose monitoring on the metabolic control of patients with type 1 diabetes. Diabetes Technol Ther 2014;16:219-223.

8. Wainstein J, Metzger M, Boaz M, Minuchin O, Cohen Y, Yaffe A, Yerushalmy Y, Raz I, Harman-Boehm I: Insulin pump therapy vs. multiple daily injections in obese Type 2 diabetic patients. Diabet Med 2005;22:1037-1046.

9. Berthe E, Lireux B, Coffin C, Goulet-Salmon B, Houlbert D, Boutreux S, Fradin S, Reznik Y: Effectiveness of intensive insulin therapy by multiple daily injections and continuous subcutaneous infusion: a comparison study in type 2 diabetes with conventional insulin regimen failure. Horm Metab Res 2007;39:224-229.

10. Aronson R, Cohen O, Conget I, Runzis S, Castaneda J, de Portu S, Lee S, Reznik Y: OpT2mise: a randomized controlled trial to compare insulin pump therapy with multiple daily injections in the treatment of type 2 diabetesresearch design and methods. Diabetes Technol Ther 2014; 16:414-420.

11. American Diabetes Association: Standards of medical care in diabetes-2014. Diabetes Care 2014;37(Suppl 1):S14-S80.

12. Mazze RS, Strock E, Wesley D, Borgman S, Morgan B, Bergenstal R, Cuddihy R: Characterizing glucose exposure 
for individuals with normal glucose tolerance using continuous glucose monitoring and ambulatory glucose profile analysis. Diabetes Technol Ther 2008;10:149-159.

13. Nathan DM, Kuenen J, Borg R, Zheng H, Schoenfeld D, Heine RJ: Translating the A1C assay into estimated average glucose values. Diabetes Care 2008;31:1473-1478.

14. UK Hypoglycaemia Study Group: Risk of hypoglycaemia in types 1 and 2 diabetes: effects of treatment modalities and their duration. Diabetologia 2007;50:1140-1147.

15. Anderson M, Powell J, Campbell KM, Taylor JR: Optimal management of type 2 diabetes in patients with increased risk of hypoglycemia. Diabetes Metab Syndr Obes 2014; 7:85-94.

16. Chow E, Bernjak A, Williams S, Fawdry RA, Hibbert S, Freeman J, Sheridan PJ, Heller SR: Risk of cardiac arrhythmias during hypoglycemia in patients with type 2 diabetes and cardiovascular risk. Diabetes 2014;63:1738-1747.

17. Khunti K, Davies M, Majeed A, Thorsted BL, Wolden ML, Paul SK: Hypoglycemia and risk of cardiovascular disease and all-cause mortality in insulin-treated people with type 1 and type 2 diabetes: a cohort study. Diabetes Care 2015; 38:316-22.

18. Lopez JM, Annunziata K, Bailey RA, Rupnow MF, Morisky DE: Impact of hypoglycemia on patients with type 2 diabetes mellitus and their quality of life, work productivity, and medication adherence. Patient Prefer Adherence 2014;8:683-692.

19. Walz L, Pettersson B, Rosenqvist U, Deleskog A, Journath $\mathrm{G}$, Wandell P: Impact of symptomatic hypoglycemia on medication adherence, patient satisfaction with treatment, and glycemic control in patients with type 2 diabetes. Patient Prefer Adherence 2014;8:593-601.

20. Ceriello A, Davidson J, Hanefeld M, Leiter L, Monnier L, Owens D, Tajima N, Tuomilehto J: Postprandial hyperglycaemia and cardiovascular complications of diabetes: an update. Nutr Metab Cardiovasc Dis 2006;16:453-456.

21. Raz I, Wilson PW, Strojek K, Kowalska I, Bozikov V, Gitt AK, Jermendy G, Campaigne BN, Kerr L, Milicevic Z, Jacober SJ: Effects of prandial versus fasting glycemia on

\section{Appendix}

\section{OpT2mise Steering Committee}

Yves Reznik, MD, Endocrinology and Diabetes Department, Centre Hospitalier Régional Universitaire de Caen Côte de Nacre, Caen, France; Ronnie Aronson, MD, FRCPC, FACE, LMC Diabetes \& Endocrinology, Toronto, Canada; Ohad Cohen, MD, Institute of Endocrinology, Chaim Sheba Medical Center, Tel Hashomer, Israel; Ignacio Conget, MD, Diabetes Unit, Endocrinology and Nutrition Department, Hospital Clínic i Universitari. Barcelona, Spain; Scott Lee, MD, Medtronic Inc., Northridge, CA; Sarah Runzis, MSc, Medtronic International Trading Sàrl, Tolochenaz, Switzerland; Simona de Portu, PharmD, MSc, Medtronic International Trading Sàrl, Tolochenaz, Switzerland; and Javier Castaneda, MSc, Medtronic Bakken Research Center, Maastricht, The Netherlands.

\section{OPT2mise Study Group}

The following primary investigators and clinical centers are listed in order of number of randomized patients: Prof. G. cardiovascular outcomes in type 2 diabetes: the HEART2D trial. Diabetes Care 2009;32:381-386.

22. Ceriello A: Point: postprandial glucose levels are a clinically important treatment target. Diabetes Care 2010;33: 1905-1907.

23. Blevins T: Control of postprandial glucose levels with insulin in type 2 diabetes. Postgrad Med 2011;123:135-147.

24. Monnier L, Mas E, Ginet C, Michel F, Villon L, Cristol JP, Colette C: Activation of oxidative stress by acute glucose fluctuations compared with sustained chronic hyperglycemia in patients with type 2 diabetes. JAMA 2006;295:1681-1687.

25. Wentholt IM, Kulik W, Michels RP, Hoekstra JB, DeVries $\mathrm{JH}$ : Glucose fluctuations and activation of oxidative stress in patients with type 1 diabetes. Diabetologia 2008;51:183-190.

26. Lepore G, Corsi A, Dodesini AR, Nosari I, Trevisan R: Continuous subcutaneous insulin infusion is better than multiple daily insulin injections in reducing glucose variability only in type 1 diabetes with good metabolic control. Diabetes Care 2010;33:e81.

27. Kilpatrick ES, Rigby AS, Atkin SL: The effect of glucose variability on the risk of microvascular complications in type 1 diabetes. Diabetes Care 2006;29:1486-1490.

28. Harrington J, Pena AS, Wilson L, Gent R, Dowling K, Baghurst P, Couper J: Vascular function and glucose variability improve transiently following initiation of continuous subcutaneous insulin infusion in children with type 1 diabetes. Pediatr Diabetes 2013;14:504-511.

29. Neylon OM, Baqhurst PA, Cameron FJ: The minimum duration of sensor data from which glycemic variability can be consistently assessed. J Diabetes Sci Technol 2014;8:273-276.

Address correspondence to: Ignacio Conget, $M D$

Hospital Clínic $i$ Universitari Villarroel 170

08036 Barcelona, Spain

E-mail: iconget@clinic.ub.es

Petrovski, University Clinic of Endocrinology, Skopje, Macedonia; Prof. Y. Reznik, CHU Côte de Nacre, Caen, France; Dr. G. Kocsis, Peterfy Hospital, Budapest, Hungary; Prof. N. Lalic, Clinical Center of Serbia, Belgrade, Serbia; Dr. H. Tildesley, ERS Endocrine Research Inc., Vancouver, BC, Canada; Prof. O. Cohen, Chaim Sheba Medical Center, Ramat Gan, Israel; Dr. B.A. Priestman, New Westminster Endocrine \& Diabetes Research Society, New Westminster, BC, Canada; Dr. M. Metzger, Diabetes Clinic, Jerusalem, Israel; Dr. Carol Joyce, Memorial University Faculty of Medicine, St. John's, NL, Canada; Dr. G. Podgorski, Greenacres Hospital, Port Elizabeth, South Africa; Dr. R. Conway, Canadian Centre for Research on Diabetes, Smiths Falls, ON, Canada; Dr. R. Aronson, LMC Diabetes \& Endocrinology, Toronto, ON, Canada; Dr. B. Perkins, Toronto General Hospital, Toronto, ON, Canada; Dr. A. Kooy, Bethesda Diabetes Research Center, Hoogeveen, The Netherlands; Dr. A. Liebl, Fachklinik Bad Heilbrunn, Bad Heilbrunn, Germany; Prof. B. Guerci, CHU de Nancy, Vandoeuvre-Les-Nancy, France; Dr. B. Bode, Atlanta Diabetes Associates, Atlanta, GA; E. Nardacci, NP, Albany Medical College, Albany, NY; Dr. A. Buchs, Assaf-Harofeh Medical Center, Zerifin, Israel; Dr. I. Harmann-Boehm, 
Soroka University Medical Center, Beer-Sheva, Israel; Dr. S. Ross, LMC Diabetes \& Endocrinology, Calgary, AB, Canada; Prof. S. Filetti, Università La Sapienza, Rome, Italy; Dr. J.F. Yale, The Research Institute of the McGill University Health Centre, Montreal, QC, Canada; Dr. I. Conget and Dra. M. Giménez, Hospital Clínic i Universitari, Barcelona, Spain; Prof. L. Distiller, Centre for Diabetes and Endocrinology, Johannesburg, South Africa; Dr. R.S. Weinstock, Upstate Medical University, Syracuse, NY; Dr. J. Zinger, Rabin Medical Center, Petah Tikva, Israel; Prof. R. Prager, City
Hospital Vienna, Vienna, Austria; Dr. O. Mosinzon, Hadassah Medical Center, Jerusalem, Israel; Dr. L. Rose, Institut für Diabetesforschung Münster GmbH, Münster, Germany; Prof. F. Giorgino, Università degli Studi di Bari, Bari, Italy; Dr. R. Alwani, IJsselland Ziekenhuis, Cappelle a/d IJssel, The Netherlands; Dr. L. Lieverse, Maxima Medisch Centrum, Eindhoven, The Netherlands; Prof. G.B. Bolli, Università di Perugia, Perugia, Italy; Dr. F. Moreau, CHU Strasbourg, Strasbourg, France; and Prof. H. Hanaire, CHU Toulouse Rangeuil, Toulouse, France. 